\title{
Social Status as Predictor of Pregnant Women Attendance at Antenatal Care
}

\author{
Agonnoudé Togbédji Maurice ${ }^{1, *}$, Assogba Abdul Koudous ${ }^{1}$, Ahouignan-Hounkponou Fanny ${ }^{2}$, \\ Houéto Sègbégnon David ${ }^{1}$, Sossa Jérôme Charles ${ }^{3}$, Zannou Gbènoukpo Sébastien ${ }^{1}$ \\ ${ }^{1}$ National School of Public Health and Epidemiology, University of Parakou, Parakou, Benin Republic \\ ${ }^{2}$ Faculty of Medecine, University of Parakou, Parakou, Benin Republic \\ ${ }^{3}$ Regional Institute of Public Health (IRSP), University of Abomey Calavi, Ouidah, Benin Republic
}

Email address:

amaurte@yahoo.fr (Agonnoude T. M.), assogba3aboudoukoudous@gmail.com (Assogba A. K.),

noumafanny@yahoo.fr (Ahouingnan-Hounkoponou F.), dhoueto@gmail.com (Houéto S. D.), sossajero@yahoo.com (Sossa J. C.),

sbastienz@yahoo.fr (Zannou G. S.)

${ }^{*}$ Corresponding author

\section{To cite this article:}

Agonnoudé Togbédji Maurice, Assogba Abdul Koudous, Ahouignan-Hounkponou Fanny, Houéto Sègbégnon David, Sossa Jérôme Charles, Zannou Gbènoukpo Sébastien. Social Status as Predictor of Pregnant Women Attendance at Antenatal Care. Central African Journal of Public Health. Vol. 7, No. 1, 2021, pp. 40-46. doi: 10.11648/j.cajph.20210701.15

Received: December 30, 2020; Accepted: January 9, 2021; Published: January 25, 2021

\begin{abstract}
Objectives: to assess the influence of social status of women on their attendance at antenatal care (ANC) in North Benin context in 2016. Methods: A cross-sectional study was conducted from November $17^{\text {th }}$ to December $16^{\text {th }}, 2016$ on a sample of 465 women who had delivered in the past few days before the survey. A structured and pre-tested questionnaire was used to collect information concerning their socio-demographic, socio-cultural, individual and community resources, and pregnancy complications. Results: Factors influencing the attendance at ANC in both univariate and multivariate analysis were number of pregnancy, the parity, the existence of a pathological obstetric history, the relationship with the head of household, the decision-making power to attend ANC, profession, income, woman's knowledge of ANC and some organizational factors (appropriateness of appointment days and waiting time). So, controlling for others factors and relative to women with the first pregnancy, women with the fifth pregnancy had 51.572 fold $(95 \% \mathrm{IC}=[7.93-335.28])$ higher odd to be non attendance to antenatal care. Conclusion: Sociocultural, political and institutional factors should be taken into account in order to improve women's attendance at antenatal care in North Benin.
\end{abstract}

Keywords: Antenatal Care, Attendance, Utilization, Social Status, Parakou, Benin

\section{Introduction}

Maternal mortality is unacceptably high. About 800 women die from pregnancy- or childbirth-related complications around the world every day [1]. In Benin, as well as in several other sub-Saharan African countries [2], the maternal mortality ratio was 405 per 100,000 live births according to WHO [3] and makes the country one of the major contributor to the worldwide death toll of mothers. The problem of maternal and perinatal deaths persists primarily due to insufficient skilled maternal antenatal care. Based on these, the WHO recommends all women should accede to antenatal care during pregnancy, skilled care during childbirth, and care and support during early postpartum. Antenatal care (ANC) is a key strategy to improve maternal and infant health. Timely and skilled management and treatment of risks ensure safe pregnancy and childbirth ${ }^{1}$. In countries with limited resources where the number of antenatal visits is already low, reduced antenatal visits is associated with an increased perinatal mortality as compared to standard care [4]. However, many pregnant women often do not achieve the recommended number of ANC visits although it is recommended that pregnant women should attend $\mathrm{ANC}$ at least 4 times during a pregnancy [5]. Antenatal care constitutes a privileged moment 
to screening for women health and socio-economic conditions likely to decrease the possibility of specific adverse pregnancy outcomes by: a) assessing general health conditions of women; b) providing therapeutic interventions known to be effective; and c) educating pregnant women about emergencies management during pregnancy, healthy eating habits, physical exercise advice as well as planning for safe birth, breastfeeding and exclusive breastfeeding education. According to Raatikainen, Heiskanen [6], even when birth takes place in hospital, non or under-attendance at antenatal care carries a substantially elevated risk of severe adverse pregnancy outcomes.

However, in Benin the proportion of mothers attending correctly ANC was low even for women with access to the services. As observed in 2011-2012 Demographic and Health Survey (DHS) [7], 58\% of mothers assisted at least four ANC with a health professional for their most recent birth. On the other hand, $0.3 \%$ of them attended ANC with unskilled non-professional staff ("matronnes" in French) while $12 \%$ of them didn't receive any antenatal care? Though ANC service utilization is very essential for improvement of maternal and child health, the use of the service is still very limited ${ }^{7}$ even for women who need and have access to the service in developing countries in general and at the Parakou town, Borgou Region (Benin) in particular. That region has one of the high proportion (24\%) of mothers who received no ANC during their most recent birth. There could be several factors that limit the attendance at ANC in the region in general, in the zone in particular which requires further study. According to Kupek et coll. (2002) and McCaw-Binns et coll. (1995) cited by Raatikainen, Heiskanen [6], some of the most pertinent studies in this field and concentrating on the risk profile of women attending late or not attending at all antenatal care, have shown that the most common barriers to attendance at antenatal care in modern western societies are lack of insurance, low income, low educational level, low social class, unmarried status, ethnic origin of the woman, difficulties in obtaining appointments and long distances. At Java-Bali region in Indonesia, Titaley, Dibley [8], found that factors strongly associated with underutilization of antenatal care services were mothers from rural areas, with low household wealth index and with low education level, and high birth rank infants with short birth interval of less than two years. Other associated factors identified included distance to health facilities, less exposition to mass media, and no obstetric complications during previous pregnancies. For Tsegay, Gebrehiwot [9], factors associated with ANC utilisation were marital status, education, proximity of health facility to the village, and husband's occupation. Apart from underutilisation of ANC by women, the quality of care and information given to them were also insufficient. The Burkina Faso DHS IV has revealed that only $53 \%$ of women were informed about complications' signs during their ANC [10].

The aim of this study was to assess the influence of social status on women's attendance at antenatal care in North Benin context.

The theoretic framework is based on Andersen and Davison model cited by Babitsch, Gohl, and von Lengerk e [11] with three components:

Predisposing factors. Individual predisposing factors (socio-demographic characteristics and mental factors) which are contextual factors predisposing the individual to the use of health services.

Enabling factors. Individual (income and wealth at an individual's will to pay for health services and the effective price of health care) and organizational (availability and organizational modalities of healthcare like means of transportation, travel time to and waiting time, amount, varieties, locations, structures and distribution of health services facilities and personnel; it also involves physician and hospital density, office hours, provider mix, quality management oversight, and outreach and education programs, health policies) factors are considered to serve as conditions enabling services utilization.

Need factors: at the individual level, they include perceived need for health services (i.e., how people view and experience their own general health, functional state and illness symptoms) and evaluated need (i.e., professional assessments and objective measurements of patients' health status and need for medical care); at the contextual level, they include environmental need characteristics (e.g., occupational and traffic and crime-related injury and death rates) and population health indices (overall measures of community health, including epidemiological indicators of mortality, morbidity, and disability).

\section{Methods}

A cross-sectional study was conducted from November $17^{\text {th }}$ to December $16^{\text {th }}, 2016$ on a sample of women who had delivered in the past few days before the survey. Parakou town is the third town with particular status in Benin Republic (after Cotonou economical capital and Porto Novo, political capital of the Republic), located in the North, 436 kilometers from Cotonou. Administratively, the town is structured into 3 districts, having 42 small rural or urban towns. The total population of the town was estimated to be 255,478 according to the fourth population and habitation survey (RGPH 4) in 2013 [12]. The majority (89.5\%) of the population lives in rural area and economically dependent on farming. Bariba $(40.4 \%)$ is the predominant ethnic group in the zone followed by Peulh (29.8\%). Islam is the most predominant religion. The town has 2 hospitals, 8 public health centers. The health facility coverage of the Parakou N'Dali health zone in 2014 was about $100 \%$. The fourth antenatal care service (CPN4) coverage was $29.7 \%$ indicating the low utilization of the services in the zone [12].

A structured and pre-tested questionnaire was used to collect quantitative data. ANC attendance, the main dependent variable was defined as: having at least four ANC visits in a health institution for checkup purpose during the last pregnancy with the following rhythm according to Benin 
health system recommendations: one in the first quarter, one in the second quarter and two in the third quarter of the pregnancy [13]. The independent variables consisted of 44 items, concerning sociodemographic (age, gestate, parity, marital status, employment, previous operations, illnesses, obstetrical history, household size), socio-cultural (ethnicity, religion or belief about pregnancy), individual resources (literacy, profession, household income, health insurance coverage, knowledge of ANC availability, advantages and modalities,) and community resources (geographical accessibility, availability of services, quality of ANC services). Informations on pregnancy complications, pregnancy complications, relative to the last pregnancy, were collected by nurses and midwives who took care of them during delivery and neonatal care.

Sample size was calculated by using Schwartz formula using a single population proportion assuming the fourth ANC visit service coverage (CPN4) to be $23.5 \%$ [14], $\alpha=0.05$ for the risk of rejecting the null hypothesis and desired margin of error of $5 \%$. Thus, the final sample size calculated was 432 . This sample size was proportionally distributed on the ten health facilities in accordance with the number of childbirth per day in each facility. In a given health center, all eligible women were enrolled until to get the desired size. A structured and pre-tested questionnaire prepared in French was used. Twenty bachelor degree epidemiologist students' interviewers, who were fluent speakers of the local languages (Bariba, Fon, Dendi) and French were given a complete training on the interview techniques and the questionnaire before data collection. The data were cleaned and coded before entering into a computer and then analyzed using SPSS software of Windows version 20.0. The significance of the differences between patterns of associated factors was tested using Chi square test with a level of significance of $5 \%$ by bivariate analysis. Odds ratio with its $95 \%$ confidence interval (CI) were calculated using binary logistic regression model in order to control confounders factors and identify the factors influencing ANC service utilization.

\section{Results}

A total of 465 parturients were interviewed. Table 1 shows the characteristics of these parturients. Most of them come from urban areas $(74.6 \%)$, without any pathological and obstetrical history $(77.6 \%)$ with a desired pregnancy $(81.6 \%)$ and declared not to have any traditional protective practice during pregnancy $(78.6 \%)$. As far as individual resources are concerned, the majority of these women have an income less than or equal to the SMIG (79.8\%), have a good knowledge of the advantages of ANC (67.9\%) and have known at least one woman who had already got a complication during pregnancy or childbirth $(84 \%)$. As for community resources, the majority of women lived within $5 \mathrm{~km}$ from the nearest health facility $(80.9 \%)$ and gave birth at the place where their pregnancy has been checked up $(81.9 \%)$.

Ninety-two percent $(92 \%)$ of them have partaken to ANC awareness sessions on pregnancy. The quality of the ANC was considered good in $83.3 \%$ of the cases.

Table 1. Descriptive characteristics of women.

\begin{tabular}{|c|c|c|c|c|}
\hline Categories of variables & & Variables and modalities & Number & $(\%)$ \\
\hline \multirow{26}{*}{ Predisposing factors } & \multirow{14}{*}{ Sociodemographic factors } & Group of age (in quartile) & & \\
\hline & & Q1 (14-21years) & 105 & 22.6 \\
\hline & & Q2 (22-25years) & 147 & 31.6 \\
\hline & & Q3 (26-29years) & 87 & 18.7 \\
\hline & & Q4 (30-43years) & 126 & 27.1 \\
\hline & & Marital status & 465 & \\
\hline & & Single, Widow or divorced & 81 & 17.4 \\
\hline & & Group of number of pregnancy (en quartile) & & \\
\hline & & $\mathrm{Q}_{1}(1)$ & 97 & 20.9 \\
\hline & & $\mathrm{Q}_{2}(2)$ & 103 & 22.2 \\
\hline & & $\mathrm{Q}_{3}(3-4)$ & 165 & 35.5 \\
\hline & & $\mathrm{Q}_{4}(5-11)$ & 100 & 21.5 \\
\hline & & Parity & & \\
\hline & & - Primiparity & 97 & 20.9 \\
\hline & \multirow{12}{*}{ Cultural factors } & Religion & & \\
\hline & & Muslim & 223 & 48.0 \\
\hline & & Christianity or animist & 242 & 52.0 \\
\hline & & Relation with the head of the household & & \\
\hline & & The woman as the head of the household & 17 & 3.7 \\
\hline & & Spouse & 343 & 73.8 \\
\hline & & Daughter & 41 & 8.8 \\
\hline & & Daughter-in-law & 64 & 13.8 \\
\hline & & Decision maker to attend ANC & & \\
\hline & & Herself & 268 & 57.6 \\
\hline & & Husband & 154 & 33.2 \\
\hline & & Father, Mother or Mother-in-law & 43 & 9.2 \\
\hline
\end{tabular}




\begin{tabular}{|c|c|c|c|c|}
\hline Categories of variables & & Variables and modalities & Number & $(\%)$ \\
\hline \multirow{32}{*}{ Facilitating factors } & \multirow{15}{*}{ Individual resources } & Education level & 465 & \\
\hline & & Illiterate & 157 & 33.8 \\
\hline & & Literate in local language or primary school & 157 & 33.8 \\
\hline & & Secondary or high school & 151 & \multirow[t]{2}{*}{32.5} \\
\hline & & Profession & 465 & \\
\hline & & House mistress & 144 & 31.0 \\
\hline & & Pupil/student/Apprentice & 61 & 13.1 \\
\hline & & Craftswoman/worker/ Liberal profession & 100 & 21.5 \\
\hline & & Civil servant & 44 & 9.5 \\
\hline & & Reseller or trader & 116 & \multirow[t]{2}{*}{24.9} \\
\hline & & Income & 465 & \\
\hline & & $40,000 \mathrm{~F}$ CFA or less & 379 & 81.5 \\
\hline & & More than $40,000 \mathrm{~F}$ CFA & 86 & \multirow[t]{2}{*}{18.5} \\
\hline & & Knowledge of ANC by women & 465 & \\
\hline & & Good knowledge & 299 & 64.3 \\
\hline & \multirow{20}{*}{ Community resources } & \multirow{2}{*}{\multicolumn{3}{|c|}{$\begin{array}{l}\text { Bad knowledge } \\
\text { Knowledge of other woman who got complications during her pregnancy or childbirth }\end{array}$}} \\
\hline & & & & \\
\hline & & No & 92 & 19.8 \\
\hline & & Yes & 373 & 80.2 \\
\hline & & Distance between home and the nearest health facility & 465 & \\
\hline & & Less than $5 \mathrm{~km}$ & 376 & 80.9 \\
\hline & & $5 \mathrm{~km}$ or more & 89 & 19.1 \\
\hline & & Appreciation by women of appointments days & 425 & \\
\hline & & No & 87 & 20.5 \\
\hline & & Yes & 338 & 79.5 \\
\hline & & Appreciation of the waiting time & 425 & \\
\hline & & Acceptable & 195 & 45.9 \\
\hline & & Long & 129 & 30.4 \\
\hline & & Too long & 101 & 23.8 \\
\hline & & Quality of ANC services & 425 & \\
\hline & & Good & 354 & 83.3 \\
\hline & & Bad & 71 & 16.7 \\
\hline \multirow{3}{*}{ Dependent Variable } & & Attendance & 465 & \\
\hline & & Good & 155 & 33.3 \\
\hline & & Bad & 310 & 66.7 \\
\hline
\end{tabular}

Table 2. Binary logistic regression of independent variables on attendance in univariate model and in multivariate model.

\begin{tabular}{|c|c|c|c|c|c|c|c|}
\hline \multirow{2}{*}{ Categories of variables } & \multirow{2}{*}{ Variables and modalities } & \multicolumn{3}{|c|}{ Univariate model } & \multicolumn{3}{|c|}{ Multivariate model } \\
\hline & & $\mathbf{N}$ & OR & 95\%CI & $\mathbf{N}$ & OR & $95 \% \mathrm{CI}$ \\
\hline \multirow{24}{*}{$\begin{array}{l}\text { Predisposing factors } \\
\text { Sociodemographic } \\
\text { factors }\end{array}$} & Household size & 465 & 1.128 & {$[1.056-1.203]$} & 425 & - & - \\
\hline & Group of age in year (in quartile) & & & & & - & - \\
\hline & $\mathrm{Q}_{1}(14-21)$ & 105 & 1 & & & & \\
\hline & $\mathrm{Q}_{2}(22-25)$ & 147 & 0.800 & {$[0.464-1.379]$} & & & \\
\hline & $\mathrm{Q}_{3}(28-29)$ & 87 & 0.541 & {$[0.297-0.985]$} & & & \\
\hline & $\mathrm{Q}_{4}(30-43)$ & 126 & 0.892 & {$[0.506-1.574]$} & & & \\
\hline & Number of pregnancy (in quartile) & & & & & & \\
\hline & $\mathrm{Q}_{1}$ (first pregnancy) & 97 & 1 & & 90 & 1 & \\
\hline & $\mathrm{Q}_{2}(2)$ & 103 & 1.306 & {$[0.739-2.308]$} & 94 & 108.961 & {$[12.36-960.84]$} \\
\hline & $\mathrm{Q}_{3}(3-4)$ & 165 & 1.952 & {$[1.151-3.313]$} & 154 & 186.971 & {$[20.89-1673.20]$} \\
\hline & $\mathrm{Q}_{4}(5-11)$ & 100 & 1.556 & {$[0.869-2.785]$} & 87 & 51.572 & {$[7.93-335.28]$} \\
\hline & Parity & & & & & & \\
\hline & - Primiparity & 97 & 1 & & 90 & 1 & \\
\hline & - Pauciparity (2 to 4 ) & 309 & 1.508 & {$[0.944-2.407]$} & 285 & 0.128 & {$[0.031-0.527]$} \\
\hline & - Multiparity (5 and more) & 59 & 2.591 & {$[1.241-5.407]$} & 50 & - & - \\
\hline & Residence area & & & & & & \\
\hline & - Urban & 345 & 1 & & 317 & 1 & \\
\hline & - Rural & 120 & 3.214 & {$[1.899-5.442]$} & 108 & 1.559 & {$[0.640-3.796]$} \\
\hline & Pathological obstetric & & & & & & \\
\hline & No & 366 & 1 & & 330 & 1 & \\
\hline & Yes & 99 & 0.439 & {$[0.279-0.691]$} & 95 & 0.319 & [0.146- 0.693$]$ \\
\hline & Desired pregnancy & & & & & & \\
\hline & No & 84 & 1 & & 78 & 1 & \\
\hline & Yes & 381 & 0.527 & {$[0.303-0.915]$} & 347 & 0.326 & {$[0.072-1.469]$} \\
\hline
\end{tabular}


The variables that influenced attendance at ANC in both univariate and multivariate analysis are gestationality, parity, the existence of a pathological obstetric history, the relationship with the head of household, the decision-making power to attend ANC, profession, income, woman's knowledge of ANC and organizational factors (adequacy of appointment days, and waiting time). Thus, controlling for other factors and as compared to primigest, women who had 2 pregnancies, between 3 and 4, as well as 5 pregnancies and more have respectively 108.961 times $(95 \% \mathrm{CI}=[12.36-$ 960.84]), 186.971 times $(95 \% \mathrm{CI}=[20.89-1673.20])$ and 51.572 times $(95 \% \mathrm{CI}=[7.93-335.28])$ more risk of being non-attendee at ANC. Tables 2 and 3 show the results of the influence of the variables.

Variables influencing attendance only in a univariate model (potential confounding factors) are household size, age of the woman, place of residence, traditional protective practices, level of education, knowledge of at least a woman who had got complications during pregnancy or childbirth and the distance between home and the health facility.

Finally, religion is revealed as the only factor influencing the attendance at ANC multivariate only: by controlling other factors, and comparing to Muslim women, Christian or Animist women are more than twice as likely to be unresponsive at $\mathrm{ANC}(\mathrm{OR}=2.107[1.023-4.340])(\mathrm{p}=0.043)$.

Table 3. Binary logistic regression of independent variables on attendance in univariate model and in multivariate model (sequence 1).

\begin{tabular}{|c|c|c|c|c|c|c|c|c|}
\hline & & \multirow{2}{*}{ Variables and modalities } & \multicolumn{3}{|c|}{ Univariate model } & \multicolumn{3}{|c|}{ Multivariate model } \\
\hline & & & $\mathbf{N}$ & OR & $95 \% \mathrm{CI}$ & $\mathbf{N}$ & OR & $95 \% \mathrm{CI}$ \\
\hline & \multirow{15}{*}{$\begin{array}{l}\text { Cultural } \\
\text { factors }\end{array}$} & Religion & & & & & & \\
\hline & & Muslim & 242 & 1 & & 220 & 1 & \\
\hline & & Christianity or animist & 223 & 0.937 & {$[0.637-1.379]$} & 205 & 2.107 & {$[1.023-4.340]$} \\
\hline & & Use of traditional protective practice during & regnar & & & & & \\
\hline & & No & 346 & 1 & & 334 & 1 & \\
\hline & & Yes & 119 & 22.263 & [8.034 -61.69] & 91 & 2.064 & {$[0.496-8.593]$} \\
\hline & & Relation with the head of the household & & & & & & \\
\hline & & The woman as the head of the household & 17 & 1 & & 15 & 1 & \\
\hline & & Spouse & 343 & 4.636 & {$[1.595-3.473]$} & 312 & 2.684 & [0.138 - 52.309] \\
\hline & & Daughter & 41 & 22.200 & {$[5.12-96.28]$} & 39 & 12.216 & {$[0.431-346.545]$} \\
\hline & & Daughter-in-law & 64 & 4.582 & {$[1.43-14.67]$} & 59 & 28.791 & {$[0.920-900.89]$} \\
\hline & & Decision maker to attend ANC & & & & & & \\
\hline & & Herself & 268 & 1 & & 252 & 1 & \\
\hline & & Husband & 154 & 7.653 & {$[4.326-13.54]$} & 131 & 2.980 & {$[1.252-7.091]$} \\
\hline & & Father, Mother or Mother-in-law & 43 & 2.048 & {$[1.023-4.097]$} & 42 & 1.320 & {$[0.292-5.972]$} \\
\hline \multirow{10}{*}{$\begin{array}{l}\text { Facilitating } \\
\text { factors }\end{array}$} & \multirow{10}{*}{$\begin{array}{l}\text { Individual } \\
\text { resources }\end{array}$} & Education level & & & & & & \\
\hline & & Illiterate & 157 & 1 & & 137 & 1 & \\
\hline & & Literate in local language or primary school & 157 & 0.536 & {$[0.307-0.935]$} & 140 & 1.046 & {$[0.416-2.629]$} \\
\hline & & Secondary or high school & 151 & 0.132 & {$[0.077-0.226]$} & 148 & 0.479 & {$[0.147-1.554]$} \\
\hline & & Profession & & & & & & \\
\hline & & House mistress & 144 & 1 & & 130 & 1 & \\
\hline & & Pupil/student/Apprentice & 61 & 0.378 & {$[0.201-0.712]$} & 57 & 0.348 & {$[0.067-1.816]$} \\
\hline & & Craftswoman/worker/ Liberal profession & 100 & 0.826 & {$[0.463-1.474]$} & 93 & 2.671 & {$[0.964-7.400]$} \\
\hline & & Civil servant & 44 & 0.268 & {$[0.132-0.542]$} & 44 & 7.438 & {$[1.668-33.180$} \\
\hline & & Reseller or trader & 116 & 0.610 & {$[0.356-1.047]$} & 101 & 1.259 & {$[0.484-3.272]$} \\
\hline
\end{tabular}

\section{Discussion}

The variables that influence attendance at $\mathrm{ANC}$ in both univariate and multivariate analysis are number of pregnancy, the parity, the existence of a pathological obstetric history, the relationship with the head of household, the decision-making power to attend ANC, profession, income, woman's knowledge of ANC and organizational factors (adequacy of appointment days, and waiting time).

By analyzing these decisive factors of women's attendance at ANC in Parakou, we see that they are women who have an income ( $>$ or $=40$ 000FCFA), who have a good knowledge of ANC (which supposes a certain level of education even if the direct role of education level is not proven in the multivariate model), who has got a desired pregnancy and the decision-making power to attend or not ANC. These elements are found by other authors. Kupek et al. (2002) and McCaw-Binns et al. (1995) cited by Raatikainen et al. [6] also found low income, low educational attainment, or poor social class, not legally married, as factors associated with low utilization of ANC services. Titaley et al. [8] at Java-Bali in Indonesia, also found the role of social status (level of wealth and education of the household). These authors also found the high rank of the child in the siblings and the short interval inter-reproductive, factors referring to the parity and access to a contraceptive method by the woman; if the second factor is not formally found in our study (even in a univariate model), the role of parity in our study goes in the same direction (in univariate, the multiparity increases the risk of non-attendance 
at ANC whereas in multivariate, pauciparity reduces the risk.

In accordance with Bourdieu's theory on the structuring of the social space, social groups or social classes are constituted in a social space with several dimensions that are capitals. These capitals which are economic (income and heritage), cultural (titles and diplomas, knowledge, know-how) and social (sustainable network of relations of mutual knowledge and inter-recognition) structure their membership in groups or social classes that in return explain their lifestyle or behavior in society. This means that in our context in Parakou, income (economic capital), occupation and knowledge of ANC (cultural capital) draw women belonging to a social group or a social class that determines their behavior vis-à-vis the attendance at ANC. Thus, relatively affluent women (income above the SMIG, a fairly high level of education, a rewarding profession, good knowledge of ANC) are more attendee at ANC than the others. This finding poses once again the problem of social inequalities of health that, since the Alma Ata Conference in 1978, are, in accordance with the principles of primary health care, unacceptable.

An individual factor which is pathological obstetric history found by other authors [8] is rather of psychological domain as pointed out by Andersen [15]. A woman, who had a problem during a previous pregnancy, remembering the experience that she had gone through, is awarer than all others on the need to properly follow her subsequent pregnancies.

The third group of factors relates to the organization of services and concerns community resources. Thus, women who are well suited to the organization set up to provide antenatal care as far as appointments and waiting time are concerned, have good attendance at ANC. These same factors are found by Raatikainen et al [6] citing Kupek et al. (2002) and McCaw-Binns et al. (1995) as for the difficulties of having appointments; on the other hand, the role of distance between pregnant women and the health facility is not found in our study.

Strength and limitations of the study: The sample size is enough to permit a good statistical power for the study. The information used is not subject to recall bias, as information collected relied on the women's record about her pregnancy. The need component is not sufficiently taken into account in our study amputating Andersen's model of some of its substance. As with any cross-sectional study, the interpretation of the causality of poor attendance at ANC is questionable because such an estimate does not lend itself to it. However, these limits do not detract from the validity of the analyses performed.

Suggestions: In order to decrease maternal morbidity and mortality, strong health systems offering accessible, available and satisfactory care are needed. This includes family planning and safe abortions as well as ANC, skilled delivery and postpartum care [10].

\section{Conclusion}

The analysis shows that non-use of antenatal care is not only the result of individual-related factors, but of different sociocultural, political and institutional factors. Our findings suggest that the antagonism of social norms surrounding pregnancy and medical conditions, as well as the failures of the health care system and the policy of exemption from preventive care during pregnancy, hinder the effective use of prenatal care [10].

\section{Authors' Contributions}

ATM and AAK participated in the conception and data analysis. AAK realized entirely the data collection. AHF supervised a whole process. ATM drafted the manuscript. HSD, SJC and ZGS reviewed the manuscript. All the authors approved the final manuscript.

\section{Conflict of Interest}

The authors declare that they have no competing interests.

\section{Acknowledgements}

We thank the staffs and Doctors of all the ten health centers in Parakou who assisted in accessing the parturient medical record. We are grateful for the contribution provided by AAK which realized the data collection for his Bachelor 'thesis.

\section{References}

[1] Sumankuuro J, Crockett J, Shaoyu W. Antenatal care on the Agenda of the Post-Millennium Development Goals in northern Ghana. International Journal of Innovation and Applied Studies 2016; 18: 341-352.

[2] Soubeiga D, Sia D, Gauvin L. Increasing institutional deliveries among antenatal clients: effect of birth preparedness counselling. Health Policy and Planning 2013; 1-10.

[3] World Health Organisation (WHO). Maternal Mortality. Data Situation by Country, Global Health Observatory (GHO).

[4] Dowswell T, Carroli G, Duley L, et al. Alternative versus standard packages of antenatal care for low-risk pregnancy. Cochrane Database of Systematic Reviews 2015; i-iii; 1-80.

[5] Bergsjø P. Est-ce que les soins prénatals aident à réduire la morbidité et la mortalité maternelle?

[6] Raatikainen K, Heiskanen N, Heinonen S. Under-attending free antenatal care is associated with adverse pregnancy outcomes. BMC Public Health; 7.

[7] Institut National de la Statistique et de l'Analyse Economique (INSAE), Macro I. Enquête Démographique et de Santé $d u$ Bénin 2011-2012. Calverton, Maryland (USA): INSAE et ICF International, 2013.

[8] Titaley C, Dibley M, Roberts C. Factors associated with underutilization of antenatal care services in Indonesia: results of Indonesia Demographic and Health Survey 2002/2003 and 2007. BMC Public Health 2010; 10: 1-10. 
[9] Tsegay Y, Gebrehiwot T, Goicolea I, et al. Determinants of antenatal and delivery care utilization in Tigray region, Ethiopia: a cross-sectional study. International Journal for Equity in Health 2013; 12: 1-10.

[10] Niang M. Le non-recours aux services de soins prénatals: expériences de femmes vivant dans la commune rurale de Kokologho au Burkina Faso. Master en Santé communautaire, Université Laval, 2014.

[11] Babitsch B, Gohl D, von Lengerke T. Re-revisiting Andersen's Behavioral Model of Health Services Use: a systematic review of studies from 1998-2011. GMS Psychosocial Medecine 2012; 2012: Doc 11.

[12] République du Bénin, Ministère de la santé. Annuaire des statistiques sanitaires 2014. Rapport annuel, Cotonou, Benin:
Direction de la programmation et de la prospective (DPP), 2015.

[13] Assogba A. Facteurs associés à l'assiduité des femmes enceintes en consultation prénatale à Parakou en 2016. Mémoire de Licence en Santé Publique, option surveillance épidémiologique, Université de Parakou, 2017.

[14] Direction Départementale de la Santé (DDS Borgou/Alibori). Annuaire statistique 2015. Rapport Annuel, Parakou, Bénin: CSPIR/ DDS Borgou/Alibori, 2016.

[15] Andersen G. Health services utilization: Framework and review. Health Services Research 1973; 184-199. 